\title{
INCIPIENT TRANSIENT DETECTION IN REACTOR SYSTEMS: EXPERIMENTAL AND THEORETICAL INVESTIGATION.
}

\section{Final Report}

July 1, 2002 to June 30, 2005

\author{
Principal Investigator: \\ Lefteri H. Tsoukalas \\ Purdue University \\ School of Nuclear Engineering \\ West Lafayette, IN 47906-1290 \\ 765-494-5742 \\ tsoukala@ecn.purdue.edu
}

Contributing Authors:

S. T. Revankar, L. H. Tsoukalas*, X Wang and R. Sattuluri

Purdue University

School of Nuclear Engineering

West Lafayette, IN 47906-1290

September 2005

* Project Director 


\section{CONTENTS}

LIST OF FIGURES

LIST OF TABLES

ACRONYMS AND ABBREVIATIONS

NOMENCLATURE

1 PROJECT SUMMARY 1

2. EXPERIMENTAL PROGRAM AND RESULTS 1

2.1 Experimental Loop $\quad 2$

2.1.1 Test Section 2

2.1.2 Water and air supply lines 2

2.1.3 Instruments and Data Acquisition 3

2.2 Data Analysis 4

2.3 Visual Observation 4

2.4 Flow Regime Identification $\quad 6$

2.5 Flow Regime Characteristics $\quad 7$

2.5.1 Bubbly Flow Data 8

2.5.2 Slug Flow Data 8

$\begin{array}{ll}\text { 2.5.3 Churn Flow Data } & 10\end{array}$

3. SEQUENTIAL PROBABILITY RATIO TEST 11

3.1 Introduction 11

3.2 Test Approach 11

3.3 Experimental Results 13

5. PROTREN SIMULATION 15

4.1 Introduction 15

$\begin{array}{ll}4.2 \text { PROTREN Structure } & 17\end{array}$

4.3 Important Features and Their Fuzzification Results 18

4.4 Importance of the Parameters and Normalization 21

4.5 Formulation of the Final Fuzzy Number with the MAX Operation 22

4.6 Experimental Results And Comparisons with SPRT 23

5 REFERENCES 26 


\section{LIST OF FIGURES}

Figure 2-1 Schematic of the experimental loop........................................................... 3

Figure 2-2 Visual flow regime map and comparison to theoretical flow map................... 5

Figure 2-3 Bubbly flow captured by the high speed camera .......................................... 6

Figure 2-4 Schematic representation of ideal slug flow ................................................. 6

Figure 2-5 Slug flow captured by the high speed camera............................................... 7

Figure 2-6 Churn flow captured by the high speed camera ............................................ 7

Figure 2-7 PDF of the void fraction and transition time for bubbly flow experimental

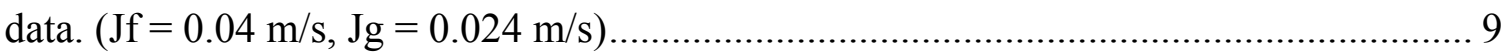

Figure 2-8 PDF of void fraction and transition time for slug flow $(\mathrm{Jf}=0.04 \mathrm{~m} / \mathrm{s}, \mathrm{Jg}=0.16$

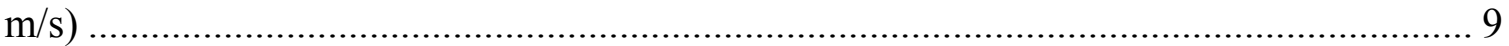

Figure 2-9 PDF of the void fraction and transition time for churn turbulent flow (Jf $=0.04$

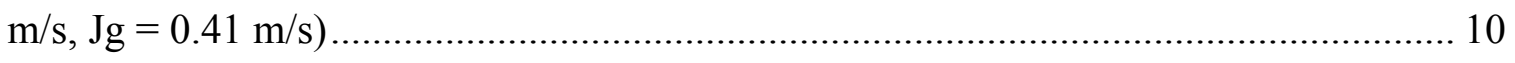

Figure 3-1 Probability density functions for slug and churn flow .................................. 14

Figure 3-2 Transition time for Slug flow (Jf $=0.014 \mathrm{~m} / \mathrm{s}, 90 \mathrm{SCFH})$............................. 14

Figure 3-3 SPRT detection of slug flow …………………….................................. 15

Figure 3-4 SPRT detection of a churn flow ............................................................. 15

Figure 4-1 Flow chart of PROTREN................................................. 19

Figure 4-2 Fusion process of three fuzzy numbers........................................................ 23

Figure 4-3 False alarm rate of identification of bubbly and slug flow slug, Case 1 ........ 24

Figure 4-4 Miss alarm rate of identification of bubbly and slug flow, Case 1 ................ 24

Figure 4-5 False alarm rate of identification of bubbly and slug flow slug, Case 2 ....... 25

Figure 4-6 Miss alarm rate of identification of bubbly and slug flow, Case $2 \quad \ldots . .25$

Figure 4-7 False alarm rate of identification of bubbly and slug flow slug, Case 3 ........ 25

Figure 4-8 Miss alarm rate of identification of bubbly and slug flow, Case 3 ................ 26

\section{LIST OF TABLES}

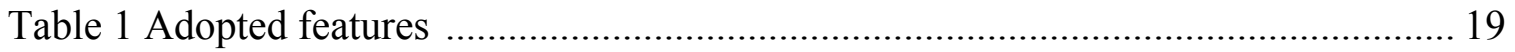

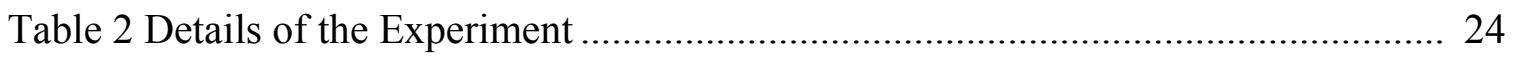




\section{ACRONYMS \& ABBREVIATIONS}

DP Differential pressure

PDF Probability density function

PROTREN Fuzzy methodology program for incipient detection of transient

SPRT Sequential Probability Ratio Testing

\section{NOMENCLATURE}

$\begin{array}{ll}\text { D } & \text { Diameter } \\ \text { d } & \text { Diameter } \\ \mathrm{g} & \text { Acceleration due to gravity } \\ \mathrm{H} & \text { Hypotheses } \\ \mathrm{j} & \text { Total Superficial Velocity } \\ \mathrm{L} & \text { Length } \\ \mathrm{m} & \text { Mean } \\ \mathrm{n} & \text { Average Sample Number } \\ \mathrm{N}_{\mu} & \text { Viscosity Number } \\ \mathrm{r} & \text { Radius } \\ \mathrm{Re} & \text { Reynolds Number } \\ \mathrm{T} & \text { Time } \\ \mathrm{v} & \text { Velocity } \\ \mathrm{V} & \text { Velocity } \\ \mathrm{a} & \text { Upper bound of SPRT } \\ \mathrm{b} & \text { Lower bound of SPRT } \\ \mathrm{H} & \text { Hypothesis } \\ \mathrm{U} & \text { Ratio of the probability of occurrence of each hypothesis at current point } \\ \mathrm{Z} & \text { SPRT Value }\end{array}$

Greek Symbols 


\begin{tabular}{|c|c|}
\hline$\alpha$ & Void Fraction, Error Probability \\
\hline$\beta$ & Error Probability \\
\hline$\sigma$ & Surface Tension \\
\hline$\Delta$ & Differential \\
\hline$\rho$ & Mass Density \\
\hline$\gamma$ & Kinematic Viscosity \\
\hline$\theta$ & Arbitrary Parameter \\
\hline$\mu$ & Viscosity \\
\hline$\xi$ & Random Number Between 0 And 1 \\
\hline \multicolumn{2}{|c|}{ Subscripts and Superscripts } \\
\hline $\mathrm{b}$ & Bubble \\
\hline $\mathrm{f}$ & Fluid \\
\hline g & Gas \\
\hline $\mathrm{i}$ & Number \\
\hline $\mathrm{m}$ & Median \\
\hline $\mathrm{n}$ & Number \\
\hline $\mathrm{p}$ & Power \\
\hline s & Slug \\
\hline $\mathrm{v}$ & Volume \\
\hline $\mathrm{TB}$ & Taylor Bubble \\
\hline $\max$ & Maximum \\
\hline $\min$ & Minimum \\
\hline
\end{tabular}




\section{PROJECT SUMMARY}

The main goal of this research was to develop a method for detecting reactor system transients at the earliest possible time through a comprehensive experimental, testing and benchmarking program. This approach holds strong promise for developing new diagnostic technologies that are non-intrusive, generic and highly portable across different systems. It will help in the design of new generation nuclear power reactors, which utilize passive safety systems with a reliable and non-intrusive multiphase flow diagnostic system to monitor the function of the passive safety systems. The main objective of this research was to develop an improved fuzzy logic based detection method based on a comprehensive experimental testing program to detect reactor transients at the earliest possible time, practically at their birth moment. A fuzzy logic and neural network based transient identification methodology and implemented in a computer code called PROTREN was considered in this research and was compared with SPRT (Sequentially Probability Ratio Testing) decision and Bayesian inference. The project involved experiment, theoretical modeling and a thermal-hydraulic code assessment. It involved graduate and undergraduate students' participation providing them with exposure and training in advanced reactor concepts and safety systems. In this final report, main tasks performed during the project period are summarized and the selected results are

presented. Detailed descriptions for the tasks and the results are presented in previous yearly reports (Revankar et al 2003 and Revankar et al 2004).

\section{EXPERIMENTAL PROGRAM AND RESULTS}

The experimental program consists of design of the experimental loop, setting up experimental procedures, performing two-phase flow test runs to generate the various flow regimes at various gas and liquid flow rates and classifying the flow regimes based on different criteria. 


\subsection{Experimental Loop}

The schematic of the experimental loop is shown in Figure 2-1. The test loop is comprised of a test section, separator, water tank, pump, air supply line, various instruments for water and airflow measurement, valves and associated piping.

\subsubsection{Test Section}

The test section is a 3" ID acrylic tube, which is mounted vertically. Air and water are supplied at the bottom of the test section and they flow vertically upwards. The entrance to the test section is constructed in such a way that will result in the proper mixing of water and air at the inlet. Water enters through 4 inlets, three on the side at equal angles from each other and a fourth inlet at the bottom of the tube. There are baffles constructed on the inside of the tube to prevent eddies or vortex formation at the inlet. There is a porous steel rod inside the tube at the inlet. Air enters at the bottom of the tube through the porous steel rod. This helps in proper atomization of the air at the inlet.

There are 4 taps on the main test section. They are used to hold conductivity probes as well as pressure taps. The first one is approximately 20 " from the bottom. The other probes are placed at a distance of 50", 80" and 130" from this probe. The total height of the test section is approximately $3.8 \mathrm{~m}$. As shown in Figure 2-1, there is a separator at the top of the test section. The separator is drum placed at the top of the test section, which is used to collect the water and air after passing through the test section. A baffle is attached to the end of the test section tube so that the excess spilling of water outside of the separator is avoided. This helps break off the flow of water. The separator is then connected to the water tank by a pipe. This completes the test section loop. With a pump at the bottom, water can now be pumped continuously through the test section.

\subsubsection{Water and Air Supply Lines}

The water supply line consists of piping and instruments from the pump to the inlet of the test section. There are two water flow lines from the pump to the inlet of the test section. The two pipes are 1" and 1.5" ID. The pipes are connected such that they can be run independently as well as together. This is done to get a wider range of water flow rate. Both the pipes are equipped with magnetic flow meters to measure the liquid flow rate. A filter is installed in the water supply line to clear out any impurities in the water. The airflow line is attached to the bottom of the test section and is checked by valves and 
rotameters. There are three rotameters in the test loop to control the airflow rate and to obtain the input airflow rate across various flow rates.

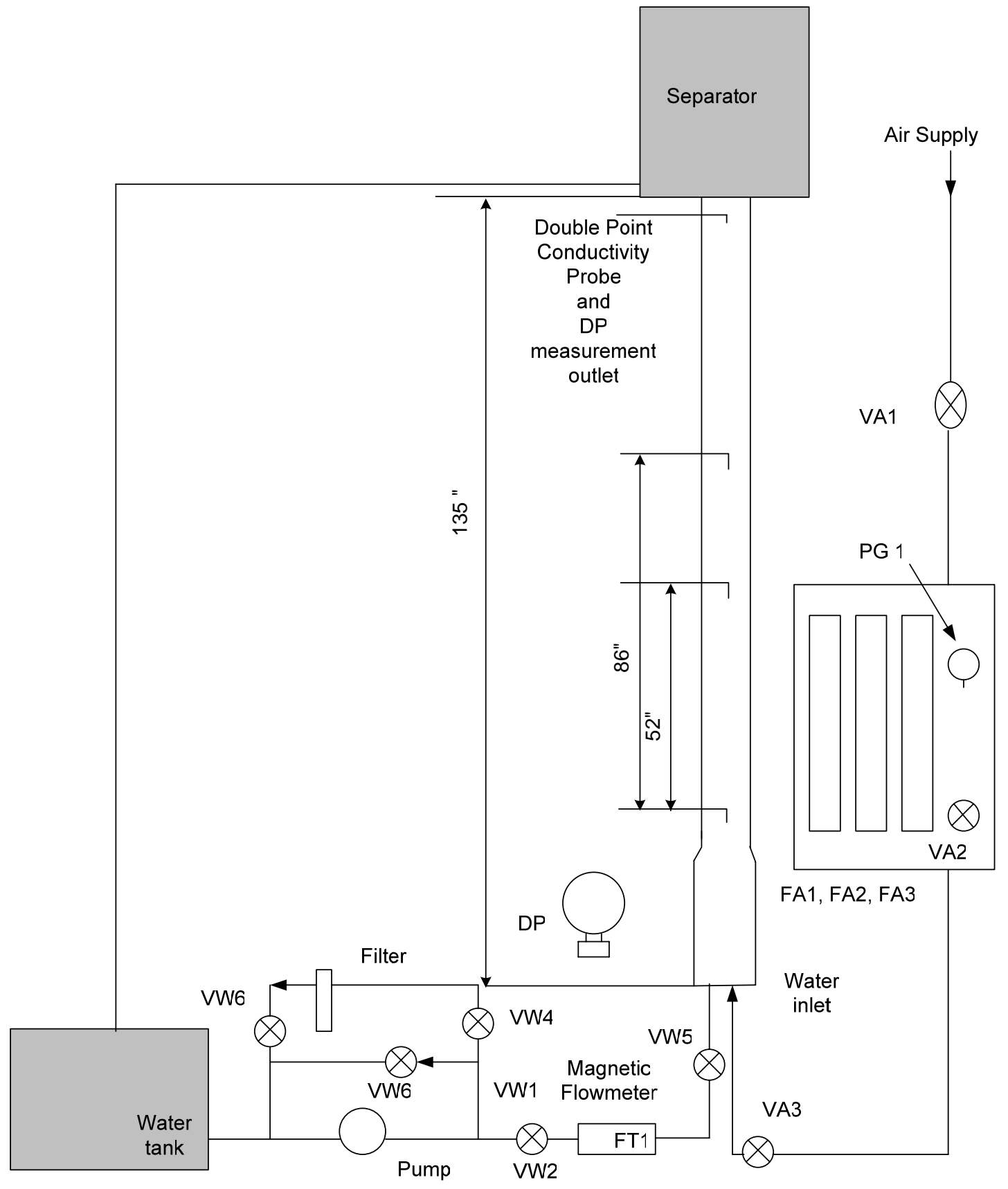

Figure 2-1 Schematic of the experimental loop

\subsubsection{Instruments and Data Acquisition System}

The experimental loop is equipped with flow meters for liquid (magnetic flow meter, rotameters) and gas (rotameters), DP transducers to measure pressure drop, two 
point conductivity probe (Revankar and Ishii 1992) to measure void fraction, interfacial area concentration and bubble velocity and size.

There are 4 conductivity probes in the experimental loop. The data from the four probes is converted into digital signals and directly recorded in a computer with the help of a data acquisition board. The experimental setup consists of Keithley's DAS-1801ST board, used with a STA $1800 \mathrm{U}$ accessory. The DAS board is capable of simultaneously obtaining data from as many as 16 single inputs or 8 differential measurements. Data is taken for 8 single inputs. The probes have two signals coming out corresponding to each probe tip. Each measurement is then coupled with ground to give us the corresponding signal. Since only the transition time (i.e. time for the bubble flow) is of interest, data is obtained from only one probe tip. Data from both the probe tips are needed for the measurement of bubble superficial velocity. An additional data acquisition device is a $\operatorname{Kodak}^{\circledR}$ motion corder analyzer. This is a high-speed camera, which can acquire visual data about the loop with speeds up to 500 frames per second. The visually recorded data is helpful in establishing a visual flow regime map for the experimental loop.

\subsection{Data Analysis}

Acquisition of the data is done with the help of a LabView ${ }^{\circledR}$ program. The frequency of the data acquisition is set by the user. This program displays the void fraction signal as obtained by the computer and then calculates the void fraction of the signal over every user-defined interval of time. For example, while collecting the data for the bubbly flow the user may desire the data acquisition to be carried out at a frequency of $10 \mathrm{KHz}$ and the void fraction to be calculated every second. The output is displayed by the program. The user can also save the conductivity probe data and the void fraction data if he so desires. In the following sections, the data is presented as it has been analyzed after acquisition and classified into different flow regimes.

\subsection{Visual Observation}

As stated earlier, the visual observation involves recording the flow regimes with the help of a high-speed camera and then based on the visual observation, classifying it into different flow regimes. As shown in Figure 2-2, the data obtained from the visual flow regime map is classified into different kinds of flow regimes. For the sake of discussion, the flow map in this case has been classified into three regions namely, 
bubbly, slug and churn flow. In the classification of the data in the test matrix, cap bubbly flow has been shown as one of the classification. The cap bubbly flow was merged with the bubbly flow to compare with the flow map available in literature. Annular flow has not been depicted in the flow map as the liquid flow rate required for annular flow regime is outside the limit of our magnetic flow meter. Visual observation has been taken for a variety of flow conditions as detailed in the test matrix. Comparison of the flow regimes and the decision based on the visual observation has resulted in the following flow regime map as shown in Figure 2-2. The flow map has been compared to the flow map obtained by Mishima and Ishii (1984).

As can be seen, the transition for bubbly to slug flow is almost at the same flow rates in both the cases. This is due to the fact that the onset of slug flow is independent of the diameter up to a pipe diameter of $10 \mathrm{~cm}$. For pipes larger than $10 \mathrm{~cm}$ in diameter, slug flow ceases to exist and the flow directly transitions to churn flow. Transition from slug to churn occurs at much lower flow rates in the case of a 3 " diameter pipe than a 1" diameter pipe.

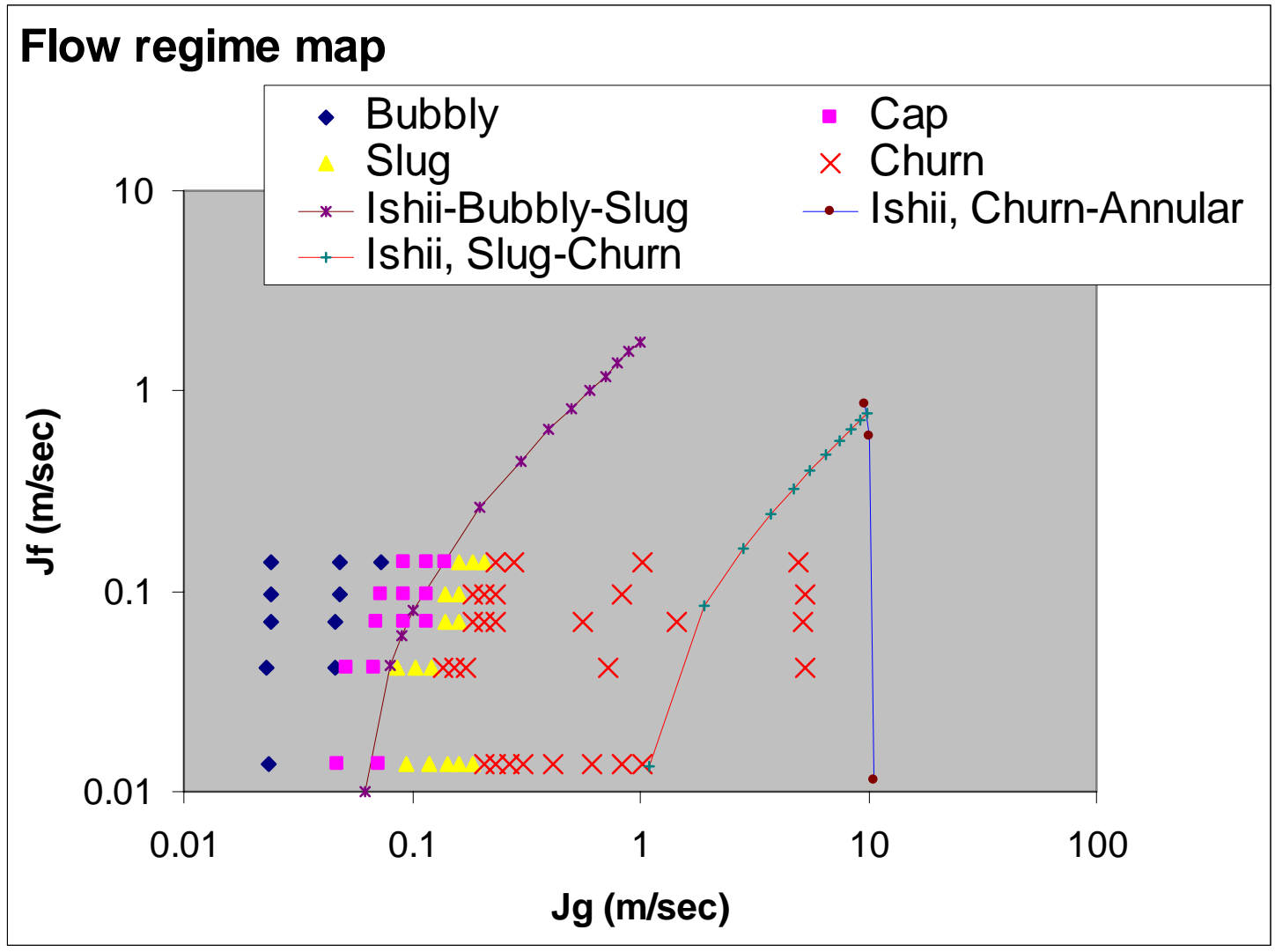

Figure 2-2 Visual Flow regime map and comparison to theoretical flow map. 


\subsection{Flow Regime Identification}

In Figures 2-3 to 2-4 the images of the flow in bubble and slug regime are shown. Bubbly flow is characterized by the flow of dispersed gas bubbles in a continuous liquid medium. The bubbles are of uniform size with no appreciable distortion. Bubble coalescence is also not observable in ideal bubbly flow. In our experiment, flow has been differentiated into only three flow regimes to make it simpler, namely, bubbly, slug and churn. Therefore, the cap bubbly data is included in the bubbly classification. A highspeed frame capture from the high-speed camera is displayed in Figure 2-3.

In ideal slug flow, a large Taylor bubble is separated by a larger number of smaller bubbles. The flow of the smaller bubbles (also called slug bubbles) is similar to the bubbly flow regime. A schematic of the slug flow depicting the Taylor bubble region and the slug bubble region is displayed in Figure 2-4 and a still frame from the experimental loop, as captured by the high-speed motion camera is shown in Figure 2-5.

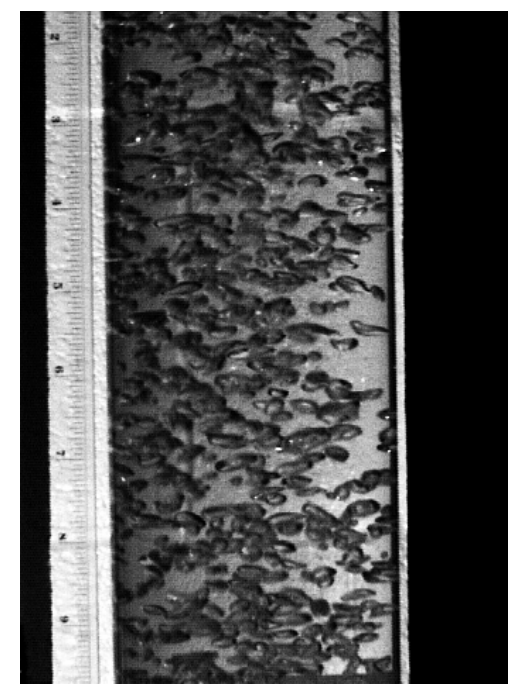

Figure 2-3 Bubbly flow captured by the high speed camera

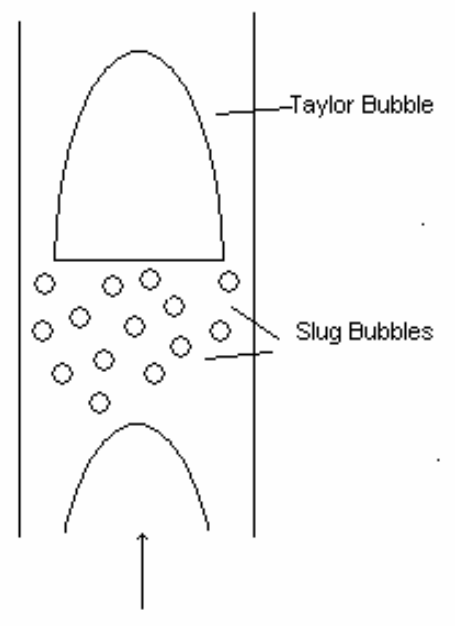

Figure 2-4 Schematic representation of ideal slug flow

As can be seen, the two figures do not closely resemble each other. This can be explained by the fact that the maximum pipe diameter for slug flow to exist is around 10 $\mathrm{cm}$ as established by Mishima and Ishii (1984). The pipe diameter in our test section is $7.62 \mathrm{~cm}$. As this is close to the slug boundary, some distortion is to be expected. 
In the ideal case, churn flow is characterized by increase in turbulence in the flow regime and thus the Taylor bubble is broken into smaller bubbles and the void fraction in the slug bubbles increases. The high-speed camera still for the churn flow case is shown in Figure $2-6$.

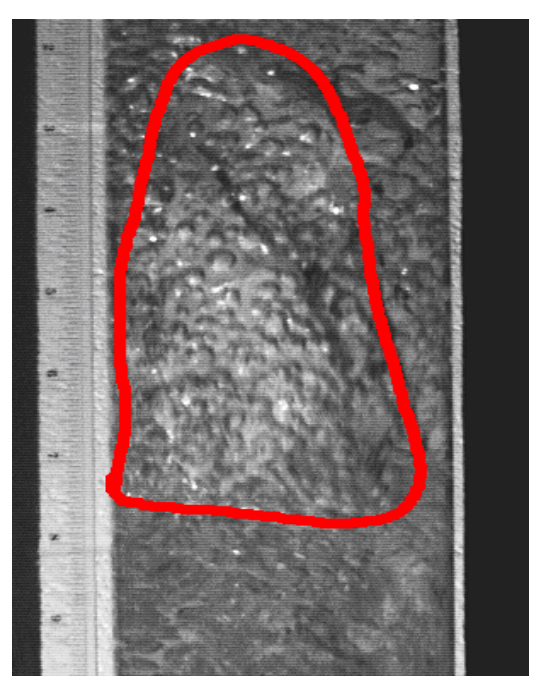

Figure 2-5 Slug flow captured by the high speed camera

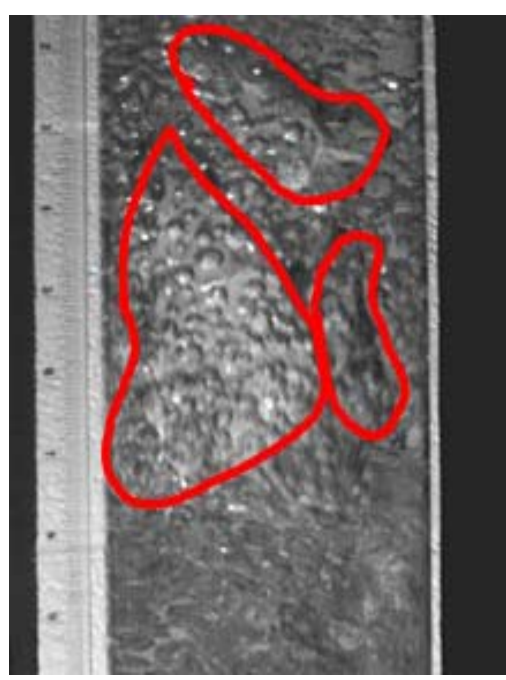

Figure 2-6 Churn flow captured by the high speed camera

\subsection{Flow Regime Characteristics}

In this section the characteristics for each of the flow regimes namely void fraction and the transition time is discussed. As can be seen from the simulated data, the characteristics of each flow regime are different. The void fraction is analyzed first. Figure 2-7 (a) represents the probability density function for the void fraction in the case of bubbly flow. As can be seen, the bubbly flow void fraction is mainly concentrated in the region below the void fraction of 0.25 . The number of zeros in the void fraction for bubbly flow a fairly high. This is due to the fact that the sampling time is 0.1 seconds instead of 1.0 seconds. The sampling time was chosen as 0.1 seconds for all flow regimes to ensure uniformity in data analysis. In Figure 8 (a) the void fraction distribution for the slug flow is displayed. This shows that the slug flow has a void concentration near the value of 1.0. The void around 1.0 signifies the Taylor bubble region. Applying a similar reasoning, a higher value of the PDF is expected around a void fraction of 1.0 in churn flow. This can be clearly seen in Figure 2-9 which shows the void fraction probability density function for a churn flow data. 
Similar analysis was carried out for the study of the transition time characteristics of the different flow regimes. The transition time data was obtained with a sampling frequency of $10 \mathrm{KHz}$. Although the signal is obtained by the LabView ${ }^{\circledR}$ program, the times when the gas phase is in contact with the probe tip, i.e. the transition times were calculated with the help of a Matlab® program. After obtaining enough transition time samples, a probability density function was calculated and the various PDFs are shown in Figures 7 (b) and 8 (b).

\subsubsection{Bubbly Flow Data}

After taking the experimental data, similar analysis is done to obtain the flow parameters similar to the ones obtained from the simulated data. The representative flow regimes as well as the void fraction distribution and the PDFs of the void fraction are detailed in the following figures. In the analysis, a PDF was obtained after analyzing a sample data consisting of over 20,000 data points. This is due to the fact that a larger data set will resolve in a smoother PDF, which is very helpful for analysis. The optimal bin size of the PDF is arrived at after a little trial and error. A small bin size results in the PDF being very jagged as there are a few samples falling into each of the bins whereas a large bin size smoothes the PDF resulting in the concealment of various important parameters of the data being analyzed.

In the Figure 2-7 (a) and (b) probability density function for the bubbly flow data is displayed. As can be expected from the flow of uniform bubbles dispersed in the liquid, the transition time is low and is not spread over a large interval of times.

\subsubsection{Slug flow data}

Similar to the bubbly flow data, slug flow data has been taken. This data is taken for the flow rate of $J f=0.04 \mathrm{~m} / \mathrm{s}$ water flow rate and $\mathrm{Jg}=0.16 \mathrm{~m} / \mathrm{s}$ air flow rate. The signal time traces are then obtained for the slug flow from the conductivity probe data. As explained earlier, the probe outputs a high voltage for airflow around the probe (bubble passing) and a low base voltage when water surrounds it. When compared to the void fraction PDF for bubbly flow, the PDF displayed by the slug flow regime displays distinctly different characteristics as in the peak close to the value of void fraction of 1.0 which is absent from the bubbly flow regime PDF for void fraction. Thus this is a distinguishing factor for differentiating bubbly and slug flow. 


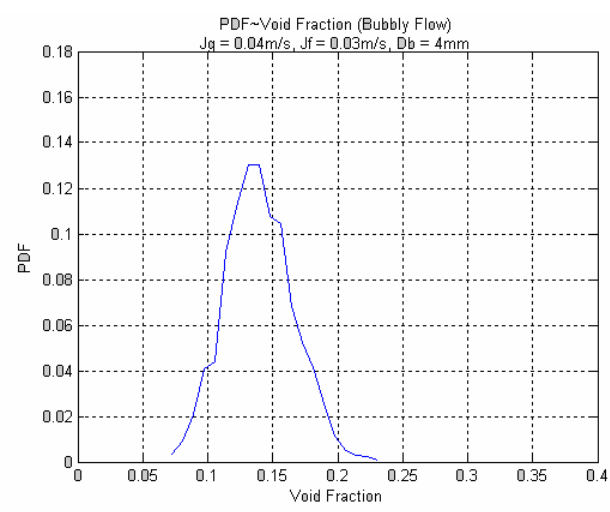

(a)

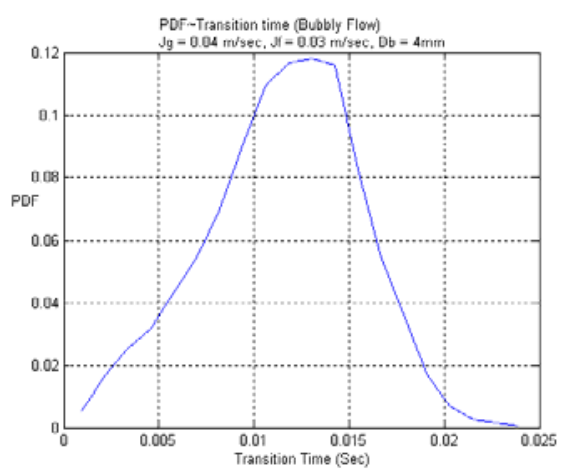

(b)

Figure 2-7 PDFs of the void fraction and (b) transition time for bubbly flow experimental data. $(\mathrm{Jf}=0.04 \mathrm{~m} / \mathrm{s}, \mathrm{Jg}=0.024 \mathrm{~m} / \mathrm{s})$

Compared to the PDF of transition time for bubbly flow, Figure 2-8, which depicts the slug flow regime has two appreciable peaks, one at a low transition time, corresponding to the slug bubbles and another peak corresponding to the Taylor bubbles. Hence this peak has a higher transition time. Thus the slug flow is easily distinguishable from the bubbly flow due to the presence of higher transition times of the Taylor bubbles.

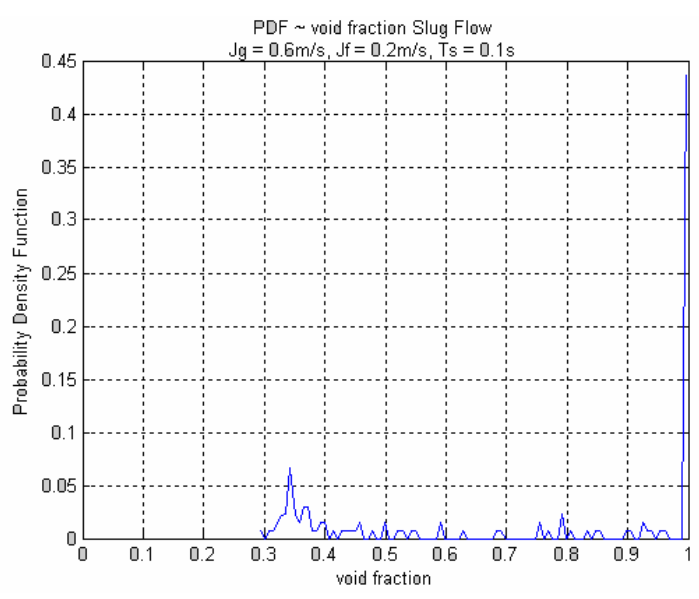

(a)

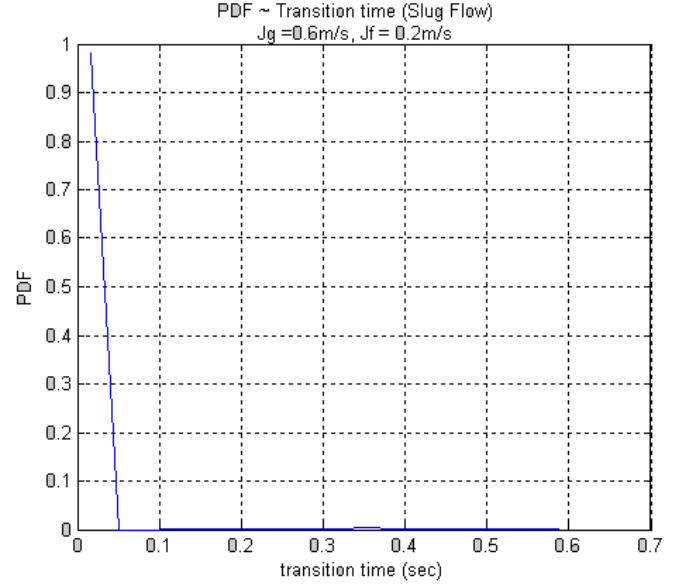

(b)

Figure 2-8 PDF of (a) void fraction and (b) transition time for slug Flow (Jf $=0.04 \mathrm{~m} / \mathrm{s}$, $\mathrm{Jg}=0.16 \mathrm{~m} / \mathrm{s})$ 


\subsubsection{Churn Flow Data}

Churn flow is similar to slug flow, except that the bubbles are more turbulent and there is more intermixing in the fluid. It is interesting to note the void fraction fluctuation for churn flow as shown in Figure 2-9 as compared to the void fraction fluctuation for the slug flow data. The void fraction shows a definite increase in the overall value as can be expected from the flow regime change from slug flow to churn flow data. The transition time also shows different characteristics, which are representative for churn flow data. It shows two definite peaks in Figure 2-9. The first peak corresponds to the smaller bubbles in the flow and the larger peak corresponds to the bigger bubbles.

In contrast to the simulated data, we have higher transition times for churn flow than for the slug flow. The reason is that the simulation is made taking into consideration a lot of simplifications in the flow. Also, the simplifying assumptions are valid to a greater extent to the flow in smaller diameter of pipes. In a larger diameter pipe, the Taylor bubble instabilities occur much earlier in the flow than for a smaller diameter pipe. This fact is corroborated from the flow regime map obtained from visual observation and its comparison to a 1" diameter flow transition. As can be seen in Figure $2-2$, the slug to churn flow transition occurs much earlier in our case than in the case of Mishima and Ishii (1984). The PDFs obtained for the void fraction and the transition time are then used for the decision making process in both SPRT and PROTREN.

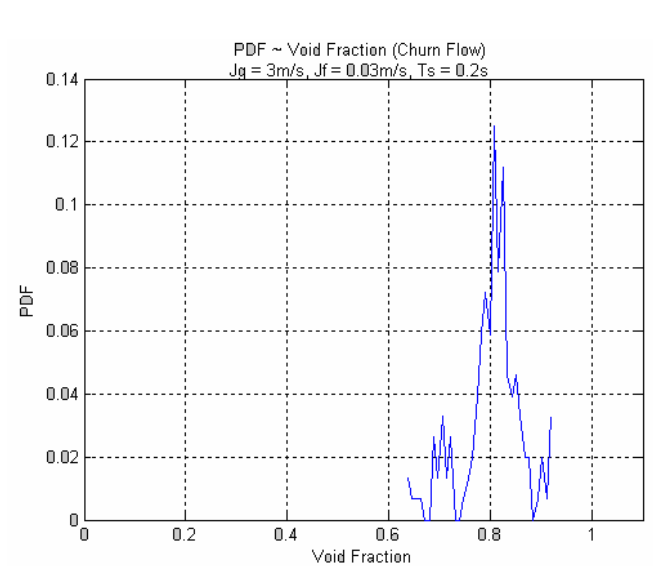

(a)

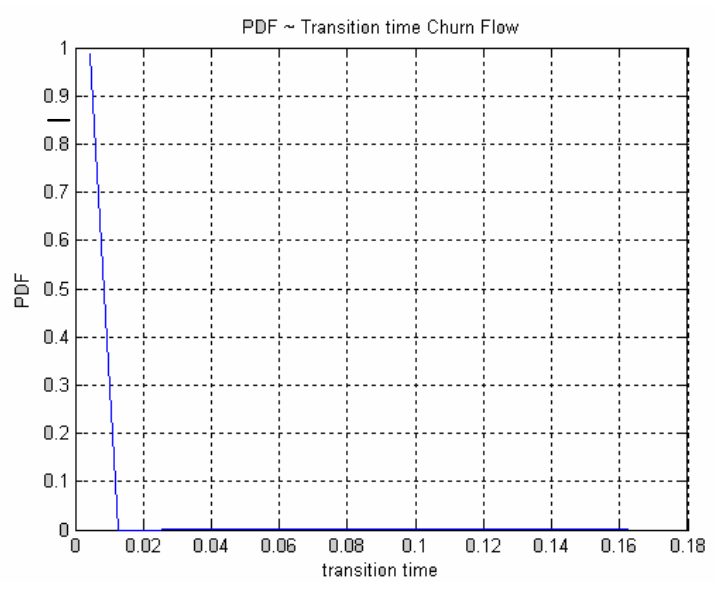

(b)

Figure 2-9 PDF of the (a) void fraction and (b) transition time for churn turbulent flow (Jf

$$
=0.04 \mathrm{~m} / \mathrm{s}, \mathrm{Jg}=0.41 \mathrm{~m} / \mathrm{s})
$$




\section{SEQUENTIAL PROBABILITY RATIO TEST}

\subsection{Introduction}

Since heat transfer and pressure drop characteristics of multiphase flow in pipes depend on the flow patterns, it is important to detect, if possible instantaneously, the flow pattern and flow pattern transition. Often the flow transition leads to operational hazards in some industrial system. This demands active control system that is reliable and robust. For control and safe operation, the active control system should receive sensor signal that indicates the flow transition or incipient to flow transition. A single point conductivity probe is considered as the sensor in our research since it is robust and its simplicity of design allows it adoption to any industrial piping.

Sequential Probability Ratio Test (SPRT) was first devised by Wald (1973). Following Wald's sequential analysis a decision test based on the SPRT has an optimal property; i.e. for given error probabilities, there is no other procedure with at least as low error probabilities or expected risk with shorter average sampling time than the SPRT. Because of this property and its inherent simplicity, the SPRT was chosen as the flow pattern annunciation tool.

The flow pattern characteristics were identified by the probe signal. For dynamic detection of the flow pattern, the SPRT method was used. The probe signal is first processed for void fraction and transition time. The signal is then subjected to the SPRT. The SPRT testing is carried out dynamically so that the flow transition detection is almost instantaneous. The primary aim in using SPRT program for the detection of transients is to be able to detect the transition earlier than other approaches. For this purpose, we utilize the transition time of the signal from conductivity probe. The transition times are obtained for representative conditions and the probability density functions are then obtained for these transition times. These probability density functions are then used as a knowledge base for distinguishing between two probability density functions.

\subsection{Test Approach}

First the conventional approach to distinguish between two hypotheses is explained followed by the approach taken in this current research to account for experimental data as well as non-Gaussian data and to get the appropriate results. 
First the simulation and experiments were carried out for all flow patterns was performed and the conductivity probe signals were obtained for the two-phase vertical flow. From the conductivity probe signals, transition time and the void fraction distribution were obtained. Since the transition time corresponds to the gas phase geometry and carries instantaneous phase information, the SPRT was fist calculated based on transition time distribution. As a first approximation, the transition time is assumed to have a normal distribution. If the transition time is non-Gaussian, the performance of SPRT using Gaussian Distribution is not significantly affected. (Humenik and Gross 1992)

The natural logarithm of probability likelihood ratio SPRT(n) was calculated as

$$
\begin{aligned}
& \operatorname{SPRT}(n)=Z_{n}=\ln \left(U_{n}\right) \\
& U_{n}=\frac{f_{n}\left(X_{i} / \theta_{1}\right)}{f_{n}\left(X_{i} / \theta_{2}\right)}=\prod_{i=1}^{n} \frac{f\left(X_{i} / \theta_{1}\right)}{f\left(X_{i} / \theta_{2}\right)} \\
& f_{n}\left(X_{i} / \theta_{j}\right)=\left(\sigma_{j} \sqrt{2 \pi}\right)^{-1} \exp \left[-\left(2 \sigma_{j}^{2}\right)^{-1}\left(X_{i}-m_{j}\right)^{2}\right.
\end{aligned}
$$

In the above set of equations the following is the terminology:

$Z_{n}$ is the value of the SPRT at stage $n$

The value of the SPRT is usually obtained by taking the logarithm of $U_{n}$. $U_{n}$ is defined as the ratio of the probability of the occurrence of each hypothesis at the current point $X_{i}$. In this case it is the ratio between the two probabilities $f_{n}$ and $\sigma$ is the standard deviation of the function and $m_{j}$ is the mean of the function

In this case, the PDFs are already established from the formulas as the mean and standard deviation of the representative flows is supposed to be known before the analysis is carried out. This is not true in the experiment where the mean and standard deviation of the PDFs are not already established.

In our case, to take into consideration, the non-Gaussian nature of the distribution of the transition time and to make the SPRT approach applicable to the experimental data, an alternate approach is taken. The bubble transition time probability density functions are first generated to represent the different flow regimes. The SPRT is then considered as a ratio of the two different kinds of flow, i.e. slug/bubbly, churn/slug etc. 
When the new transition time sample is obtained to be analyzed and the flow regime is to be determined, the PDF corresponding to the new sample in the case of both the flow regimes is obtained. The logarithm of this ratio then is a measure of the SPRT. This value is then compared to the limits of the SPRT. If the values are within the limits $(a, b)$, then the flow is undecided and another sample is required. This process is continued till the value of SPRT crosses one of the limits and a decision can be made.

At the current point, the limits for the error probabilities are set at 0.05 each which results in the values of $b=-2.95$ and $a=+2.95$. This establishes the limits until which SPRT will evaluate the signal to decide on the flow regime. Once the value of SPRT crosses the threshold limits, the SPRT program can make a decision and can identify the flow regime or changes in the flow regimes.

In this simulation, by counting the total gas phase number in a given time, the sampling intervals can be converted to sampling time. For example, in the bubbly flow, there are an average of 15 bubbles per second. In this way, the sampling interval can be converted into sampling time. Instead of presenting the results in terms of the actual time, the results have been presented in terms of sample number or the bubble sequence number. Taking into account the average number of bubbles per second as well as the time for transition for the bubbles, the SPRT decision can be reached as to when the change has occurred in the system.

\subsection{Experimental Results}

Figure 3-1 shows the PDF characteristics for both slug and churn flow. As can be seen, there is not much of a difference between both flow characteristics with regards to the low transition time region. The main decision is made based on the higher transition times i.e. those of the Taylor Bubbles. The slug flow shows a distinct transition time around 0.1-0.2 whereas the churn flow transition time has a peak around 02-0.3 (Figure 3-2). SPRT program written for distinguishing the experimental data has results as shown in Figure 3-3 and Figure 3-4. In Figure 3-3 distinction is made between the slug and churn flow when the input is comprised of slug flow. As can be seen there are a few false alarms in this case. But they seem to be within the accepted limit for proper detection of the flow. Figure 3-4 shows the flow identification when churn flow is input into the program and distinction has to be made between slug and churn flow. In this case, there 
are more miss alarms than in the case of slug flow data. This can be explained by the fact that the churn flow PDF covers the PDF generated by the slug flow and hence some of the data points belonging to churn flow will be classified as slug flow.

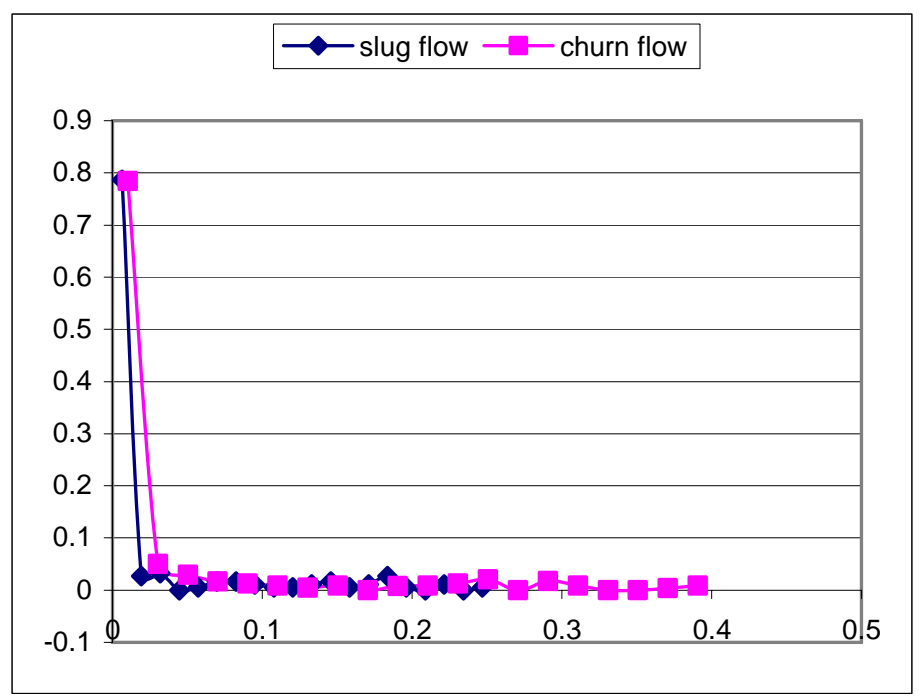

Figure 3-1 Probability density functions for slug and churn flow

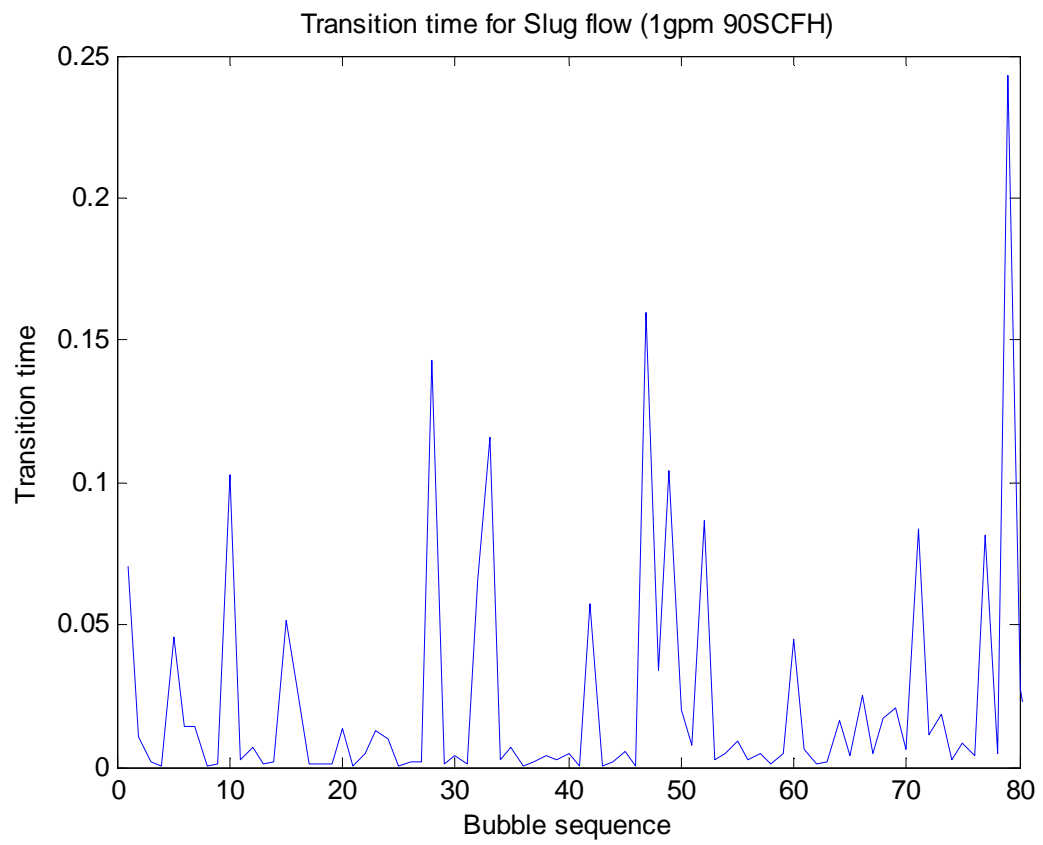

Figure 3-2 Transition time for slug flow (Jf $=0.014 \mathrm{~m} / \mathrm{s}, 90 \mathrm{SCFH})$ 


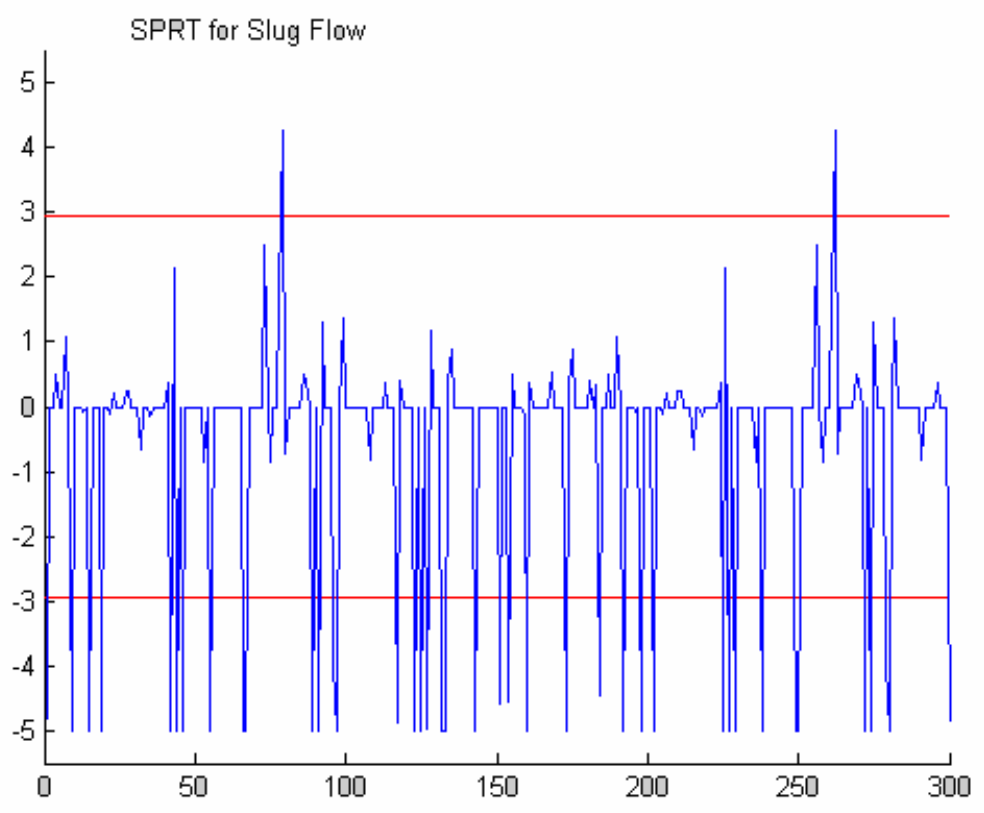

Figure 3-3 SPRT detection of detection of slug flow SPRT for distinguishing between Chum and Slug Flow

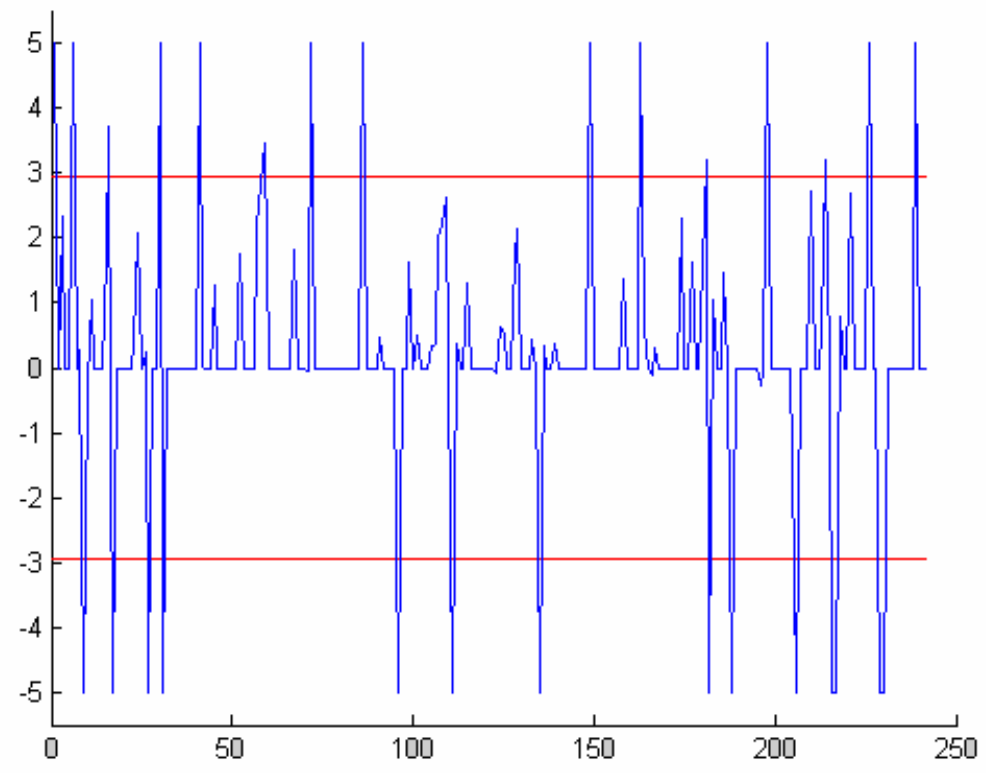

Figure 3-4 SPRT detection of a churn flow

\section{PROTREN SIMULATION}

\subsection{Introduction}

Argonne National Laboratory, Exelon and Purdue University have collaborated on developing a knowledge-based system called IGENPRO intended to provide reliable 
process diagnostics and management. IGENPRO can be used in nuclear power plants to provide real-time operator assistance during off-normal thermal-hydraulic plant transient conditions. IGENPRO is composed of three modules: PROTREN, PRODIAG and PROMANA (Mormon et al 1997; Mormon et al 1998; Wang et al 1999). The first module PROTREN provides trending information. It classifies incoming signals into transient or steady state categories (Wang et al 2001). PROTREN is designed to be used in various circumstances without too much modification.

Artificial neural network (ANN) is the critical part of this research work. ANN-based truth decision curves form the core of the fuzzy inference module and hence affect the system performance. ANNs are similar to real neurons in human. Each neuron has input and output connections with weights assigned to them. Usually, the ANN is composed of layers of neurons and it needs a training process before used. The objective of the training process is to find a set of weights which minimizes the mean square error of the training sets. And it is expected that this optimization is effective for other similar data. It has been proved that ANNs are capable of simulating any nonlinear functions. In addition, ANNs simulate learning process of human being and they are mathematical model free (Tsoukalas and Uhrig, 1997).

Another important tool for simulating the computational performance of the human brain is fuzzy logic. It is well known that human being is good at handling fuzzy concepts, uncertain and even conflicting information. Fuzzy logic technology is a candidate which enables computer programs to 'think' like a person (Tsoukalas et al, 1997).

Wavelet, as a recently developed time-frequency transformation tool, has been the most successful advance in signal processing. It supports multi-resolution analysis of localized information. Therefore wavelet analysis can be very useful in break point detection and discontinuity identification. For detection problems, wavelet packet transform is usually utilized to redistribute the energy of signal on the time-frequency plane and it usually has the advantage of obtaining more energy concentration than wavelet transform. Then the important transient information could be extracted and better performance is expected. In this research, the wavelet coefficients present as a major feature extracted from online signals. 
The existing transient detection methodologies are most statistics based. Sequential Probability Ratio Test (SPRT), which takes the advantage of the likelihood ratio of two probability distributions, is the optimum for Gaussian processes and the benchmark that every new methodology needs to beat. In this paper, we also compare our results with those from SPRT.

\subsection{PROTREN Structure}

In order to obtain timely and reliable trend information from incoming on-line signals, a feature-based methodology is developed which detects emerging trends based on the information contained in the current and a few recent sample points. All existing methods utilize one specific feature. These methods are optimal in some limited circumstances but fail when some strict assumptions are not satisfied. Better result may be obtained if multiple features are observed spontaneously, especially when some uncertain information, which would fail most optimal methods, exists. In addition, feature-based methodology makes it possible to develop process-independent systems. Process-dependent detectors focus only on some specific feature so that the performance is guaranteed only in limited situations. If multiple features are utilized and the inference engine can adjust itself online and always choose the most appropriate feature, detectors can be process-independent.

However, there are some difficulties when multiple features are concerned. The first difficulty happens when different features provide conflicting information. Artificial intelligence can be applied to solve this problem. Fuzzy logic technology is capable of simulating experts' inference to handling conflicting information. It does not necessarily provide best performance in some limited cases. Fuzzy logic provides limited optimal decision-making process, which makes transient detector more robust and reliable. The second difficulty of developing this new system is that the objective of this methodology is to hard code as few as possible process dependent information such as parameters, equations. Instead, more useful features and important general rules are utilized. ANN technologies provide the system learning ability and allow the system to adjust itself online.

The whole process is described in Figure 4.1. Various features are extracted from the incoming signals. One set of the data is fed into wavelet preprocess module where 
wavelet coefficients are generated. Another set of the data is used to extract other statistical features. The last set of data is fed into the truth decision curve (TDC) generator where TDCs are generated. Altogether six features are generated in this stage. The features are fed into the next stage to obtain truth values of various features. The truth values are generated based on truth decision curves, which come from TDC generator module. Six triangular fuzzy numbers are generated from truth values. Then the information contained in the fuzzy numbers is fused into one final fuzzy number. The final decision is made in the decision-making module based on the final fuzzy number. There is another module called weight adjustor. The weights of the various features are utilized in the fuzzy fusion process. And the weights are also adjusted online according to the performance of the system. The adjustor makes the features that give correct decisions higher weight and the features that give wrong decisions lower weight. The details will be introduced in the following sections.

\subsection{Important Features and Their Fuzzification}

It is well understood that decisions made by humans are based on a few of the most important attributes. To simulate the behavior of human decision strategy, a feature extractor is the first essential step. It is desirable to present the input data in a form of a pattern vector of a lower dimensional whose elements represent only the most significant aspects.

In this subsection, we are going to show the six important parameters used to capture the features of the signal and illustrate how these parameters are mapped into membership functions. Each parameter holds a particular piece of evidence. The final decision for the onset of a trend calls for fusing all pieces of evidence together in an efficient and timely manner.

The features are summarized in the Table 4.1. Due to the limitation of the space, we will introduce part of the features only. The definition can be found in references. 


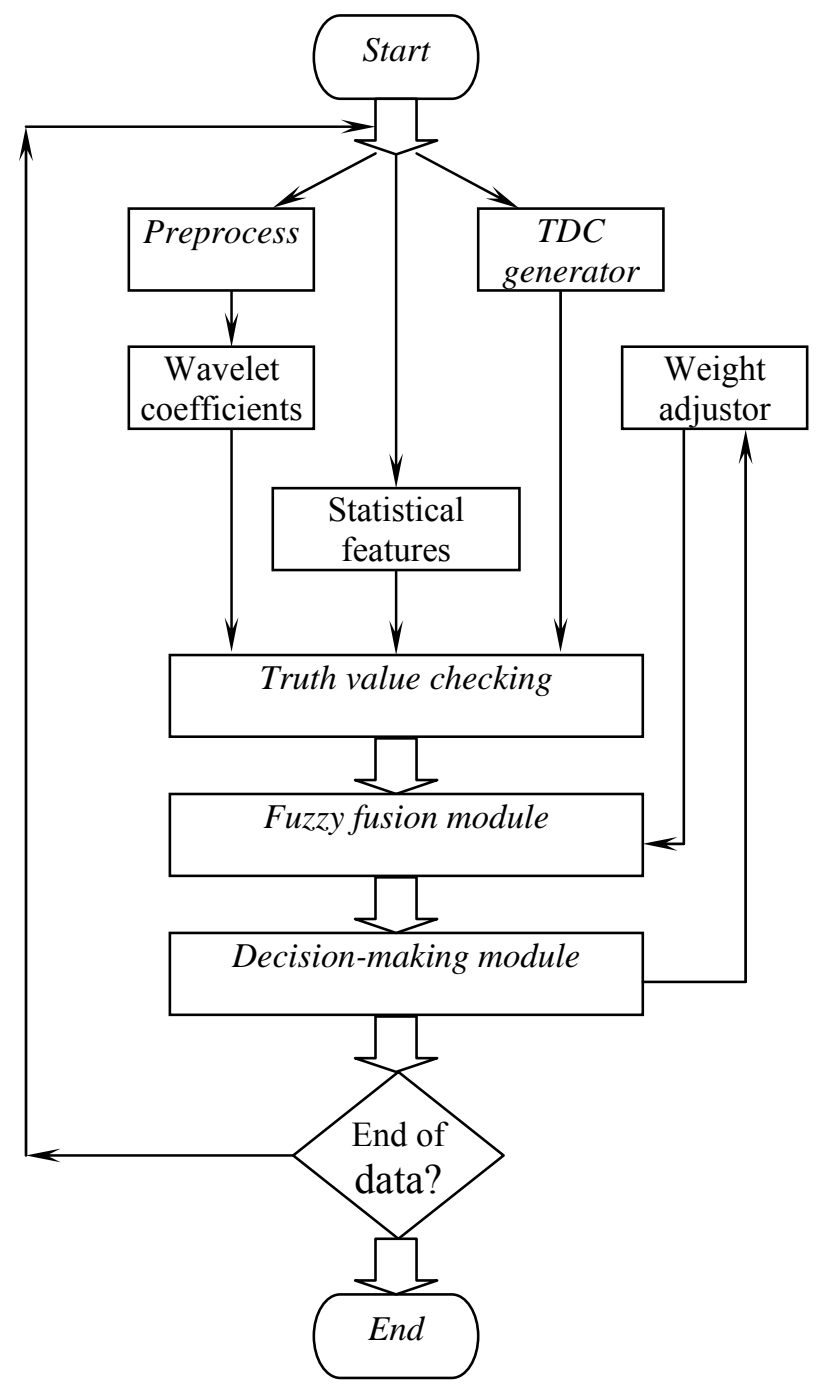

Figure 4.1 Flow chart of PROTREN

Table 4.1 Adopted features

\begin{tabular}{|c|c|l|}
\hline & Feature & \multicolumn{1}{|c|}{ Description } \\
\hline 1 & $p d f$ & Probability density function \\
\hline 2 & cum_pdf & Cumulative probability density function \\
\hline 3 & pdfofavg & Average of probability density function \\
\hline 4 & $l k$ & Likelihood ratio \\
\hline 5 & $m o m 3$ & The third moment \\
\hline 6 & $w c o$ & Wavelet coefficients \\
\hline
\end{tabular}


Instantaneous signal changes are recorded and accumulated in the third parameter. By accumulating the signal changes it becomes possible to make decisions based on not only the instantaneous signal changes, e.g., the $p d f$, but also on the recent history of the signal. This feature is very sensitive for transient signals distributed with multiple peaks in $p d f$.

Likelihood ratio is an efficient feature. Decisions can be made in the quickest manner if the probability distribution is known for transients and noise. In practice the logarithm format of the likelihood ratio is usually used.

The last feature contains the wavelet coefficients. Wavelet packets transform is performed. The coefficients are utilized to check if there is abnormal energy existing in the frequency domain. The detail definitions of these features can be found in references (Wang et al, 2001).

To obtain the confidence, the original value needs to be fuzzified as fuzzy concepts in advance, and then the fuzzy rules are applied. In the new methodology, this process is simulated with a truth decision mapping curve, which is obtained based on ANN technology. To implement this mapping process, several truth decision curves are generated based on online data sets. This generation process can happen either in a separate training stage or in application stage.

Truth decision curves represent relationships between value of features and their corresponding fuzzy numbers, in which membership information can be found. For mathematical convenience, triangle fuzzy numbers are adopted in the system. Therefore the fuzzy number as well as the final decision is determined only by truth decision curves in addition to the value of features. In another word, truth decision curves are the most critical part of this fuzzy system because fuzzy rules are integrated into these curves and these curves as a whole play a role of inference engine.

After the values of the features are obtained, they are fed into these mapping functions (truth decision curves). The truth decision curves, which simulate some specific fuzzy rules, provide some subjective judgments. In the case of signal detection problem, these subjective judgments represent the confidence of the system about an occurrence of a transient. The subjective judgment is called truth. Its value is limited to [-1 1]. This mapping process transform the information included in various features into a uniform 
domain. Based on the truth values, several fuzzy numbers are developed and the final fuzzy number is derived through MAX process. Final decisions are obtained based on the final fuzzy number.

\subsection{Importance of the Parameters and Normalization}

There are two kinds of uncertainty handled in this fuzzy methodology. One is caused by the signal itself such as unknown onset of transients, unknown type of transients, additive noise and measurement error. Another is caused by the uncertainty about the fuzzy rules. Triangular fuzzy numbers handle the first type uncertainty. The membership from 0 to 1 reflects the influence of uncertain factors included in the signals. However, the uncertainty about the fuzzy rules cannot be found in fuzzy numbers. Other researchers solved this kind of uncertainty by Type-2 fuzzy logic systems (Mendel, 2000; Tsoukalas, et al 1997). In these systems, the uncertainty of fuzzy rules is represented by another set of membership functions. In the decision making module, Type-2 fuzzy numbers are transformed into Type-1 fuzzy numbers first. Then defuzzification process is applied on the Type-1 fuzzy numbers. The whole process is complicated. In our methodology, instead of using Type-2 fuzzy numbers, the weight of the fuzzy numbers is utilized to reflect the uncertainty of the fuzzy rules.

In fuzzy systems, every parameter includes useful information and none of them provides dominant contribution. Therefore, all the rules are fired to some extend. More reliable rules are given higher weights. On the other hand, less reliable rules have lower weights. Generally, the parameters that represent cumulative information play a more important role than the others and the parameters that represent time rate of changes are less important due to the uncertainty of additive noise. The parameters' importance reflects experts' confidence on the different fuzzy rules which are developed based on the features. More important parameters give more accurate results. The importance of fuzzy rules does not influence the shape of the fuzzy numbers because it is difficult to integrate the importance of each feature into the generation process of truth decision curves. Instead, they make functions in the data fusion process. In addition, the weights are not always constant. They will be adjusted online with some self-learning algorithm. If in some tests several rules give wrong decisions and others give correct decisions, the weights of the former are decreased and those of the latter are increased. 
4.5 Formulation of the Final Fuzzy Number with the MAX Operation.

When a final fuzzy number is computed to incorporate the partial information provided by the six fuzzy numbers associated with the six parameters, the following fuzzy rules are applied:

Rule 1: If any of the features provide very high confidence of occurrence of a transient, then a transient decision may be made.

Rule 2: If some of the features provide high confidence and they have been proved to be effective (large weight in this case), then a transient decision may be made.

Rule 3: If all of the features provide high confidence and they have been proved to be effective (large weight in this case), then a transient decision is made.

Rule 4: If some of the features provide low confidence and they have been proved to be effective (large weight in this case), then a steady state decision may be made.

Rule 5: If all of the features provide low confidence, then a steady state decision is made.

These fuzzy rules are implemented with a MAX operation process. All the five rules are considered when the information in the six fuzzy numbers is fused. The basic process is described as follows.

$$
\mu_{\text {final }}(x)=\underset{i=1-n}{\vee} \mu_{i}(x)
$$

where,

$$
\begin{array}{ll}
n & =\text { number of features used } \\
\mu & =\text { membership of a point on the truth domain } \\
x & =\text { a point on the truth domain }[0,1]
\end{array}
$$

It should be addressed that as mentioned in preceding section, the weights of these fuzzy numbers are not same. Some of the features have high weights and the others have low weights. The weights show up here in an intensity manner. Therefore there are two values corresponding to each point in the truth domain. One is membership and the other is intensity. The value of intensity is derived as follows.

$$
\operatorname{in}(x)=\max \left(w_{i}\right) \quad \text { where } \quad \mu_{\text {final }}=\mu_{i}
$$

An example of this operation has been shown in Figure 4.2. There are three fuzzy numbers fused in this example, the weights of these three fuzzy numbers are 0.6, 0.8 and 
1 respectively. The final fuzzy number is obtained with the 'MAX' operation. However, the intensity in different part of the final fuzzy number may be different. In this process, the uncertainty of the signal as well as that of the rules is taken into consideration. The final decision is made on the basis of this new fuzzy number through a centroid defuzzification process.

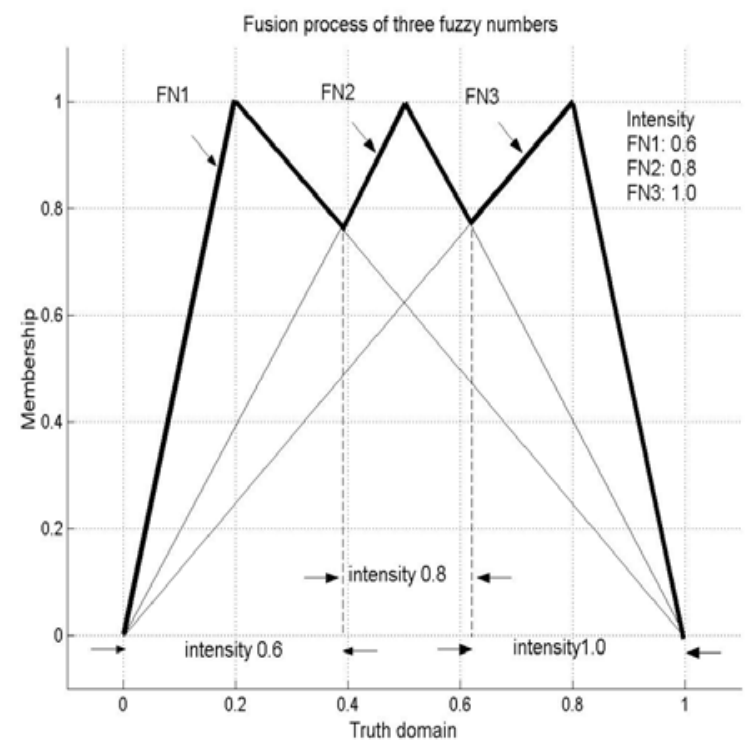

Figure 4.2. Fusion process of three fuzzy numbers

\subsection{Experimental Results And Comparisons With SPRT}

A lot of experiments have been performed to test the efficacy of this methodology (Sattuluri, 2004). Because the truth decision curves used are obtained from online signals, this methodology can adapt itself to different circumstances without changing mathematical model like other methodologies. One set of results are shown in this paper. The details are shown in Table 2. In this experiment, bubbly flow, slug flow and churn flow are distinguished using void fraction data. Because the flow regimes are identified by pairs, the whole experiment can be divided into three parts. In all of these parts, the training sets contain 21000 data points and the test sets contain 4000 data points. The false alarm and miss alarm are obtained for each part. The results are also compared with those from SPRT. The results are shown in Figure 4.3 to Figure 4.8. 
Table 4.2. Details of the experiment

\begin{tabular}{|c|c|c|c|c|}
\hline Case 1 & Steady & Transient & Training & Test \\
\hline 1 & Bubbly & Slug & 21000 & 4000 \\
\hline 2 & Bubbly & Churn & 21000 & 4000 \\
\hline 3 & Slug & Churn & 21000 & 4000 \\
\hline
\end{tabular}

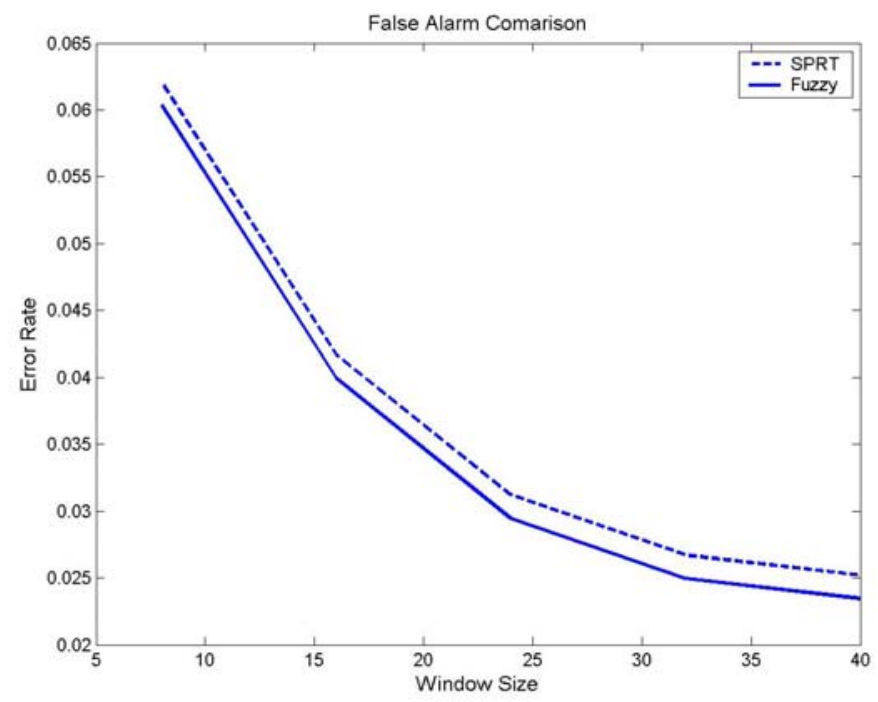

Figure 4.3. False alarm rate of identification of bubbly and slug flow, Case 1

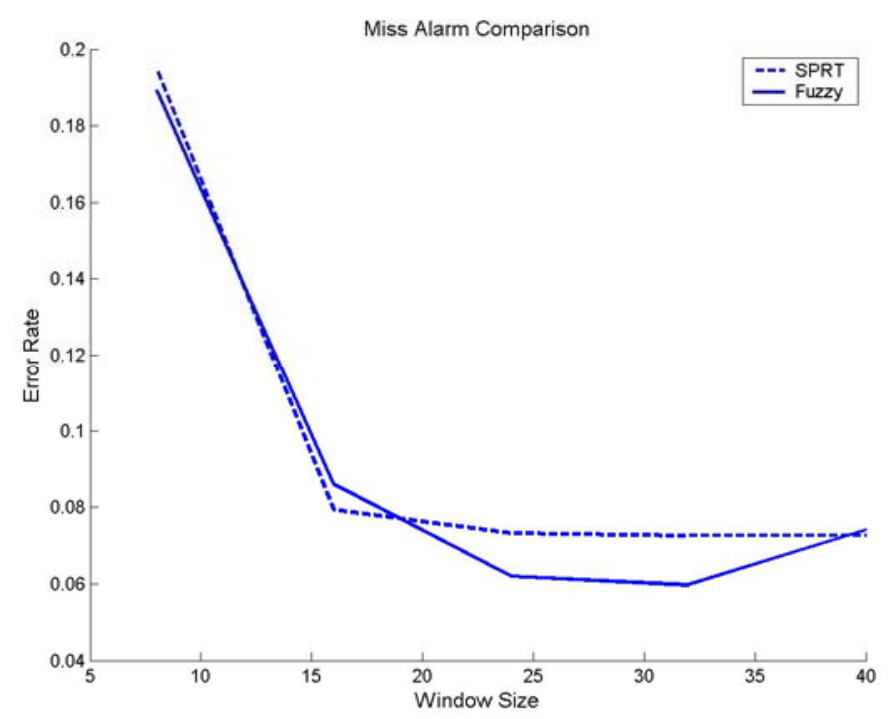

Figure 4.4. Miss alarm rate of identification of bubbly and slug flow, Case 1 


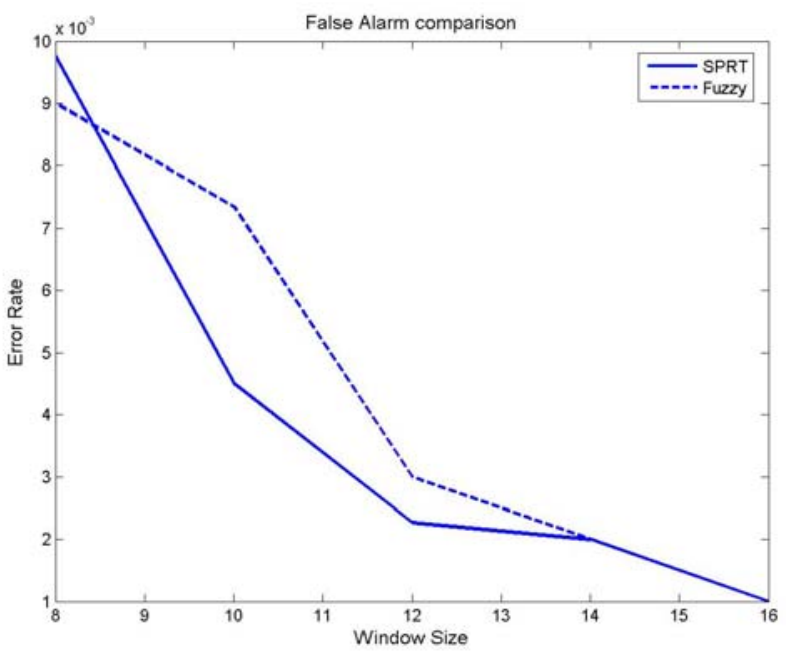

Figure 4.5 False alarm rate of identification of bubbly and slug flow, Case 2

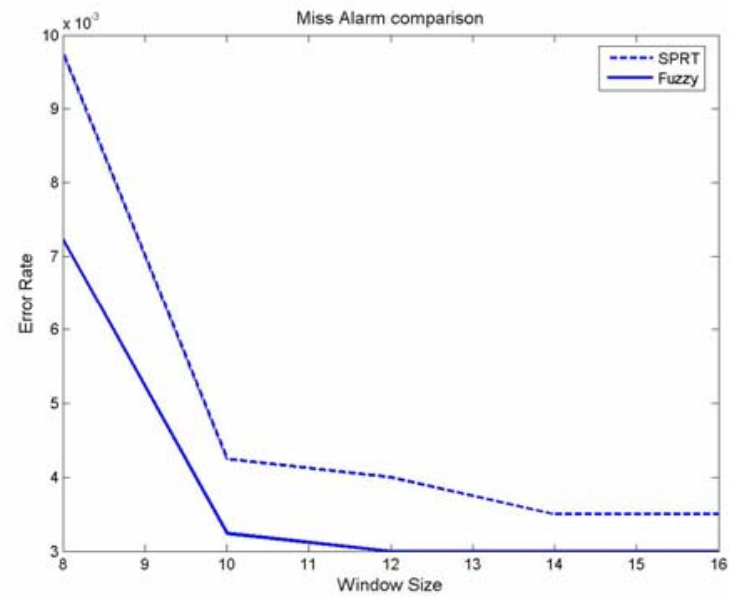

Figure 4.6. Miss alarm rate of identification of bubbly and slug flow, Case 2

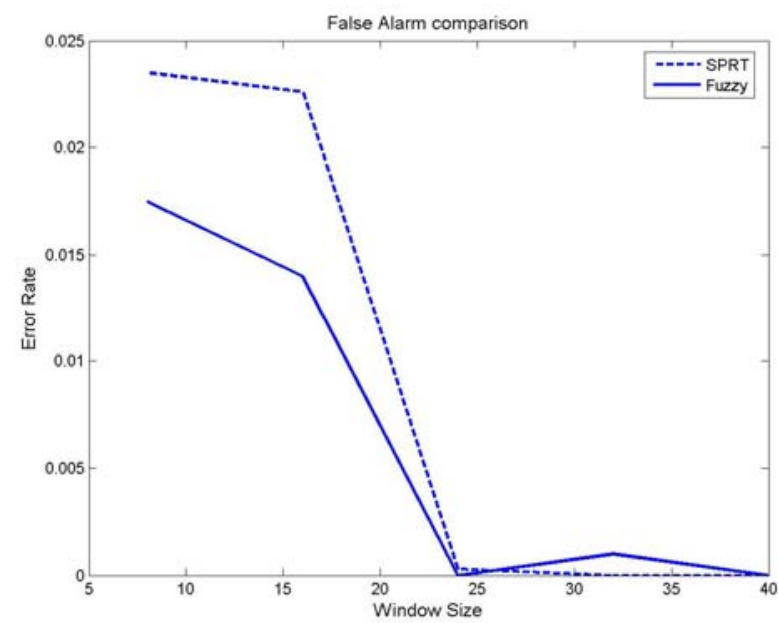

Figure 4.7 False alarm rate of identification of bubbly and slug flow, Case 3 


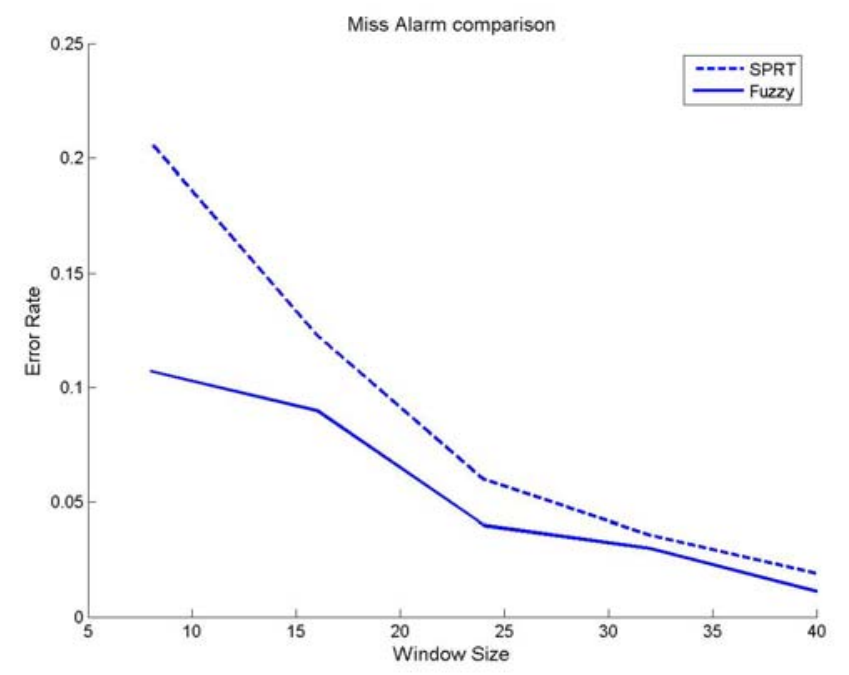

Figure 4.8. Miss alarm rate of identification of bubbly and slug flow, Case 3

The results show that the error rate of the neurofuzzy methodology is about $80 \%$ on average of those using SPRT, which is the optimum statistical based method. Part of the improvement is due to the imperfection of $p d f$ obtaining process in SPRT. Another important reason is that our methodology relates more information in the data.

\section{REFERENCES}

Mendel J. M. 2000, Uncertainty, Fuzzy Logic, and Signal Processing, Signal Processing, Vol. 80, pp. 913-933.

Humenik, Keith. Gross, Kenny C.,1992, Using Fourier Series Methods to Reduce Correlation of Nuclear Power Reactor Data, Nuclear Science \& Engineering vol. 112 No.2 pp 127-35.

Mishima, K., Ishii, M. 1984, Flow Regime Transition Criteria for Upward Two Phase Flow in Vertical Tubes, International Journal of Heat and Mass Transfer Vol. 27. 723737.

Morman J. A., Reifman J., Vitela J. E., Wei T. Y. C., Applequist C. A., Hippley P., Kuk W. and Tsoukalas L. H., IGENPRO Knowledge-Based Digital System for Process Transient Diagnostics and Management," Proceedings of the IAEA Meeting on 
Advanced Technologies for Improving Availability and Reliability of Current and Future Water Cooled Nuclear Power Plants, Argonne, IL, September 8-11, pp. 213-224, 1997. Morman J. A., Reifman J., Vitela J. E., Wei T. Y. C., Chai J. and Tsoukalas L. H., 1998, IGENPRO Knowledge-Based Operator Support System, Proceedings of ANS International Meeting on Safety of Operating Reactors, San Francisco, CA, October 1114, pp. 516-523.

Revankar S. T. and Ishii M.,1992, Local interfacial area measurement in bubbly flow, Internat. J. Heat Mass Transfer, Vol. 35, pp 913-925.

Revankar S. T., Tsoukalas L. H. and Sattuluri R, 2003, Incipient Transient Detection In Reactor Systems: Experimental And Theoretical Investigation, Yearly Progress Report, July 1, 2002 to September, 2003 PU/NE-03-11, October,2003 .

Revankar S. T., Tsoukalas L. H. and Sattuluri R, 2004, Incipient Transient Detection In Reactor Systems: Experimental And Theoretical Investigation, Second Year Progress Report July 1, 2003 to June 30, 2004 PU/NE-04-12, October, 2004.

Sattuluri R., 2004, Detection of Incipient Transients in Two Phase flow, Master Thesis, Purdue University.

Tsoukalas L. H., Ishii M., Mi Y., 1997,A Neurofuzzy Methodology for Impedance-based Multiphase Flow Identification, Engng Applic. Artif. Intell. Vol. 10, No. 6, pp545-555.

Tsoukalas L. H., Uhrig R. E., 1997, Fuzzy and Neural Approaches in Engineering, Wiley, New York, 1997.

Wald, A. 1973, Sequential Analysis. New York: Dover.

Wang X., Wei T. Y. C., Reifman J. and Tsoukalas L. H., 2001, An Innovative FuzzyLogic-Based Methodology for Trend Identification, Nuclear Technology, Vol. 135, pp. 64-87.

Wang X., Wei T. Y. C., Reifman J. and Tsoukalas L. H., 1999, Signal Trend Identification with Fuzzy Methods, Proceedings of IEEE International Conference on Tools with Artificial Intelligence, Chicago, IL, November 9-11, pp. 332-335. 